\title{
Test for positional candidate genes for body composition on pig chromosome 6
}

\author{
Cristina Óvilo ${ }^{\mathrm{a} *}$, Angels Oliver ${ }^{\mathrm{b}}$, \\ José Luis Noguera ${ }^{\mathrm{c}}$, Alex Clop ${ }^{\mathrm{d}}$, Carmen BArragán ${ }^{\mathrm{a}}$, \\ Luis VArona ${ }^{\mathrm{c}}$, Carmen Rodríguez ${ }^{\mathrm{a}}$, Miguel Toro ${ }^{\mathrm{a}}$, \\ Armand Sánchez ${ }^{\mathrm{d}}$, Miguel Pérez-EnCiso ${ }^{\mathrm{c}}$, Luis Silió ${ }^{\mathrm{a}}$ \\ ${ }^{a}$ Departamento de Mejora Genética Animal, SGIT-INIA, 28040 Madrid, Spain \\ ${ }^{\mathrm{b}}$ Centre de Tecnologia de la Carn, IRTA, 17121 Monells, Girona, Spain \\ c Area de Producció Animal, Centre UdL-IRTA, 25198 Lleida, Spain \\ ${ }^{\mathrm{d}}$ Departament de Ciència Animal i dels Aliments, \\ Universitat Autònoma de Barcelona, 08193 Bellaterra, Barcelona, Spain
}

(Received 9 August 2001; accepted 14 February 2002)

\begin{abstract}
One QTL affecting backfat thickness (BF), intramuscular fat content (IMF) and eye muscle area (MA) was previously localized on porcine chromosome 6 in an $F_{2}$ cross between Iberian and Landrace pigs. This work was done to study the effect of two positional candidate genes on these traits: $H-F A B P$ and $L E P R$ genes. The QTL mapping analysis was repeated with a regression method using genotypes for seven microsatellites and two PCR-RFLPs in the $H$ $F A B P$ and $L E P R$ genes. $H-F A B P$ and $L E P R$ genes were located at 85.4 and $107 \mathrm{cM}$ respectively, by linkage analysis. The effects of the candidate gene polymorphisms were analyzed in two ways. When an animal model was fitted, both genes showed significant effects on fatness traits, the $H-F A B P$ polymorphism showed significant effects on IMF and MA, and the LEPR polymorphism on BF and IMF. But when the candidate gene effect was included in a QTL regression analysis these associations were not observed, suggesting that they must not be the causal mutations responsible for the effects found. Differences in the results of both analyses showed the inadequacy of the animal model approach for the evaluation of positional candidate genes in populations with linkage disequilibrium, when the probabilities of the parental origin of the QTL alleles are not included in the model.
\end{abstract}

candidate gene / H-FABP / LEPR / QTL / pigs

\footnotetext{
* Correspondence and reprints
}

E-mail: ovilo@inia.es 


\section{INTRODUCTION}

Two different approaches are being used for the application of DNA technology to ascertain the genetic basis of production and quality traits and the development of DNA tests as selection tools in farm animals. The first is the identification of genomic regions related to quantitative traits using DNA markers (QTL mapping), and the second is the detection of mutations in candidate genes and their association with economic traits.

Many different porcine experiments have succeeded in the identification of QTLs that are mainly related to backfat and growth traits, and to the analysis of families created from crosses of divergent breeds $[4,25]$. We have previously reported the results of a QTL detection project, aimed at the identification of productive and quality QTLs on an $\mathrm{F}_{2}$ cross between Iberian and Landrace pigs. With this material, we were able to identify a QTL on chromosome 6 affecting backfat thickness, intramuscular fat percentage and eye muscle area with a high significance level [24]. This trait is one of the main factors influencing the eating quality (tenderness, juiciness and flavor) of pork meat and products [23] and it is presently receiving more attention in pig breeding schemes [16]. Due to the demand for inexpensive and lean pork during the last decades, a considerable reduction of the fat content of carcasses has been registered in pig populations [11]. But the presence of intramuscular fat has also been reduced and a lot of criticisms have been raised by consumers about the decline of pig meat quality [28].

The use of the results of QTL detection experiments is a complex job which ideally requires the identification of the gene or genes underlying the QTL. For this task the positional candidate gene approach could give much more useful results since we can potentially use the positive associations directly in breeding programs. Several candidate genes related with meat quality and fatness traits could be identified from current genetic maps. On porcine chromosome 6 , the heart fatty acid binding protein $(H-F A B P)$ and the leptin receptor gene $(L E P R)$ are considered candidate genes for this QTL due to their position and physiological role.

The $H$-FABP gene codes for a protein related to the intracellular transport of fatty acids in skeletal muscle and plays an important role in the regulation of lipid metabolism. Polymorphisms in this locus have been associated with fatness traits in the Duroc breed and Meishan crossbred pigs $[8,9]$ and in Duroc $\times$ Landrace pigs [13].

The leptin receptor gene (LEPR), also located on chromosome 6 [5], is related to the control of feed intake and the regulation of energy balance in mammals since it modulates the leptin effect. Leptin and leptin receptor genetic variants are associated with obese phenotypes in humans and mice and are expected to influence fat deposition in pigs [6]. The influence of $L E P R$ 
Table I. Traits analyzed with their mean, standard deviation and number of $F_{2}$ individuals with records.

\begin{tabular}{lcccc}
\hline Trait & & $N$ & Mean & $\sigma_{y}$ \\
\hline Intramuscular Fat $(\%)$ & IMF & 449 & 1.51 & 0.56 \\
Backfat Thickness (mm) & BF & 464 & 28.71 & 8.12 \\
Eye Muscle Area $\left(\mathrm{cm}^{2}\right)$ & MA & 448 & 33.97 & 5.08 \\
Carcass Weight $(\mathrm{Kg})$ & $\mathrm{CW}$ & 464 & 74.69 & 10.06 \\
\hline
\end{tabular}

gene variants on fatness variation was demonstrated recently in an experimental cross of the Berlin Miniature pig and Duroc breeds [18].

Differences in voluntary feed intake between the parental populations support the consideration of the $L E P R$ gene as a candidate in this experimental intercross. In a recent work, Morales et al. [21] found a 30\% higher voluntary feed intake in Iberian than in Landrace pigs fed ad libitum. Observed breed differences in fatness [26] could be partially attributed to differences in feeding behavior, and leptin and related proteins would be involved, due to their physiological role.

The objectives of this work were the linkage mapping of $H-F A B P$ and $L E P R$ loci, and the evaluation of these two genes as candidates for the fatness variation observed in our experimental population. A more accurate estimation of the position and effect of the QTL was performed by genotyping a higher number of $F_{2}$ animals.

\section{MATERIALS AND METHODS}

The experimental population comes from the cross of three Iberian boars (Guadyerbas line) with 30 Landrace sows (Nova Genetica) to produce the $\mathrm{F}_{1}$ population, in which six males and 64 females were mated to produce an $\mathrm{F}_{2}$ population of 577 animals. The parental Landrace line has been selected for feed conversion efficiency and lean content and is a population with reduced appetite and fat reserves. The Iberian boars used were unselected animals with an extremely fatty body composition. Parental populations were checked to be free of the malignant hyperthermia gene mutation (RYRI). Animal management and slaughter, and phenotypic data obtention of Carcass Weight (CW), Intramuscular Fat Percentage (IMF), Backfat Thickness (BF) and Eye Muscle Area of the Longissimus dorsi muscle (MA) are described in Ovilo et al. [24]. Phenotypic means and standard deviations of the traits are shown in Table I.

For the QTL mapping analysis, seven microsatellites of chromosome six were genotyped in all the parental and $F_{1}$ animals and $369 F_{2}$ animals. The 
microsatellites used were $S 0035, S w 1057, S 0087, S w 316, S 0228, S w 1881$ and $S w 2419$. Information of the genotypes for $H-F A B P$ and $L E P R$ polymorphisms from all the parental and $F_{1}$ animals and the number of $F_{2}$ pigs shown in Table $I$ were also included as markers in the statistical analysis for QTL detection. Microsatellite typing was performed in the same way as described in Ovilo et al. [24].

Linkage analysis was performed using the "build" option of the CRI-MAP 2.4 program [12]. Marker information content in the $\mathrm{F}_{2}$ was obtained as described in Knott et al. [19]. The QTL analysis was carried out with a regression model described in Haley et al. [17], in which it is assumed that putative QTLs are diallelic with alternative alleles fixed in each parental breed. The linear model was:

$$
\mathrm{Y}=\text { sex }+ \text { family }+ \text { covariate }+c_{\mathrm{a}} \mathrm{a}+c_{\mathrm{d}} \mathrm{d}+\mathrm{e}
$$

where $y$ is the phenotype, sex and family are the fixed effects, $a$ is the additive effect, $\mathrm{d}$ is the dominant effect and e is the residual effect. Covariates used were the carcass weight for BF, IMF and MA, and also backfat thickness for IMF and MA. The coefficients $c_{\mathrm{a}}$ and $c_{\mathrm{d}}$ were calculated as follows:

$$
\begin{aligned}
& c_{\mathrm{a}}=\operatorname{pr}(\mathrm{QQ})-\operatorname{pr}(\mathrm{qq}) \\
& c_{\mathrm{d}}=\operatorname{pr}(\mathrm{Qq})
\end{aligned}
$$

where $\operatorname{pr}(\mathrm{QQ})$ is the probability of being homozygous for the Iberian origin, $\operatorname{pr}(\mathrm{qq})$ is the probability of being homozygous for the Landrace origin, and $\operatorname{pr}(\mathrm{Qq})$ is the probability of being heterozygous. Thus, the genotype of the putative QTL is calculated as conditional upon the marker genotypes at each $\mathrm{cM}$. The model was fitted every $\mathrm{cM}$, testing the models with and without the QTL effect with an F test.

Genome wide and chromosome wide significance thresholds were calculated by permutation techniques [3], permuting the measures 20000 times within family and sex along the 18 autosomes. The $5 \%, 1 \%$ and $0.1 \%$ genome wide thresholds were $8.53,10.39$ and 13.07 respectively.

The 95\% confidence intervals for the location of the QTLs were obtained by the chi-square drop approximation [20]. The limits were obtained at the chromosome locations where the F statistic decreased 1.92 units in both directions.

The $H$-FABP polymorphism analyzed is a HaeIII restriction site polymorphism located at position 1810-1813 in the second intron of the gene (accession number Y16180). This polymorphism has two alleles: $D$ (with fragments of $684 \mathrm{bp}, 117 \mathrm{bp}$ and $16 \mathrm{bp}$ ) and $d$ (with fragments of $405 \mathrm{bp}, 279 \mathrm{bp}, 117 \mathrm{bp}$ and $16 \mathrm{bp}$ ). The genotyping was performed as described previously by Gerbens et al. [7], with minor modifications. 
For the analysis of the LEPR gene one PCR-RFLP was essayed on the same animals. The polymorphism analyzed is a HpaII restriction site polymorphism [27] located in the fourth intron of the gene (accession numbers AJ223162 and AJ223163). The polymorphism has two alleles: $A$ (with a fragment of $2 \mathrm{~Kb}$ ) and $B$ (with fragments of 1450 and $550 \mathrm{pb}$ ).

Two other PCR-RFLPs described in the H-FABP gene (HinfI and MspI) and one in the $L E P R$ gene (RsaI) were also tested and discarded for this study due to their low polymorphism in the cross.

Two approaches were realized for the two candidate genes. In the first one, an association statistical analysis was performed with the PEST software [15], by fitting the PCR-RFLP as a fixed effect in the model. Pedigree information was included from the $F_{0}, F_{1}$ and $F_{2}$ generations. The variance components for the analyzed traits were estimated by REML using the VCE 4.2.5 program [22]. The linear model used included sex (two levels), batch (eight levels) and genotype as fixed effects. The $H-F A B P$ and $L E P R$ genotype association analysis was performed for the four traits recorded using the carcass weight as the covariate. The genotype effect on IMF was also analyzed with a model including BF as the covariate instead of $\mathrm{CW}$.

In the $H-F A B P$ analysis, for each analyzed trait two contrasts were estimated: the additive effect measured as half of the difference between homozygous genotypes $(D D-d d) / 2$, and the dominance effect, estimated as the deviation of the heterozygous genotype from the mean of the homozygous genotypes $(D d-0.5(D D+d d))$. For the LEPR analysis, only two genotypes were present in the $\mathrm{F}_{2}$ population due to the low frequency of allele $A$, and so only one contrast could be made: the difference between the two available genotypes $(B B-A B)$. The statistical significance of the contrasts was established by an $\mathrm{F}$ test.

The second approach was to repeat the QTL regression analysis but including, for the $H-F A B P$ polymorphism, two additional covariates that define the additive (1, $0,-1$ for $D D, D d$ and $d d$, respectively) and the dominance effects ( 0,1 and 0 for $D D, D d$ and $d d$, respectively). For the $L E P R$ polymorphism, the two available genotypes were included as fixed effects in the QTL regression model. Statistical significance of the covariates was established by a t test.

\section{RESULTS}

\subsection{Linkage mapping}

The linkage map obtained with the seven microsatellites of chromosome 6 , H-FABP-HaeIII RFLP and LEPR-HpaII RFLP was in agreement with those of other studies with respect to the order and distances between markers (http://www.ri.bbsrc.ac.uk/pigmap/). The map obtained allowed us to locate the 


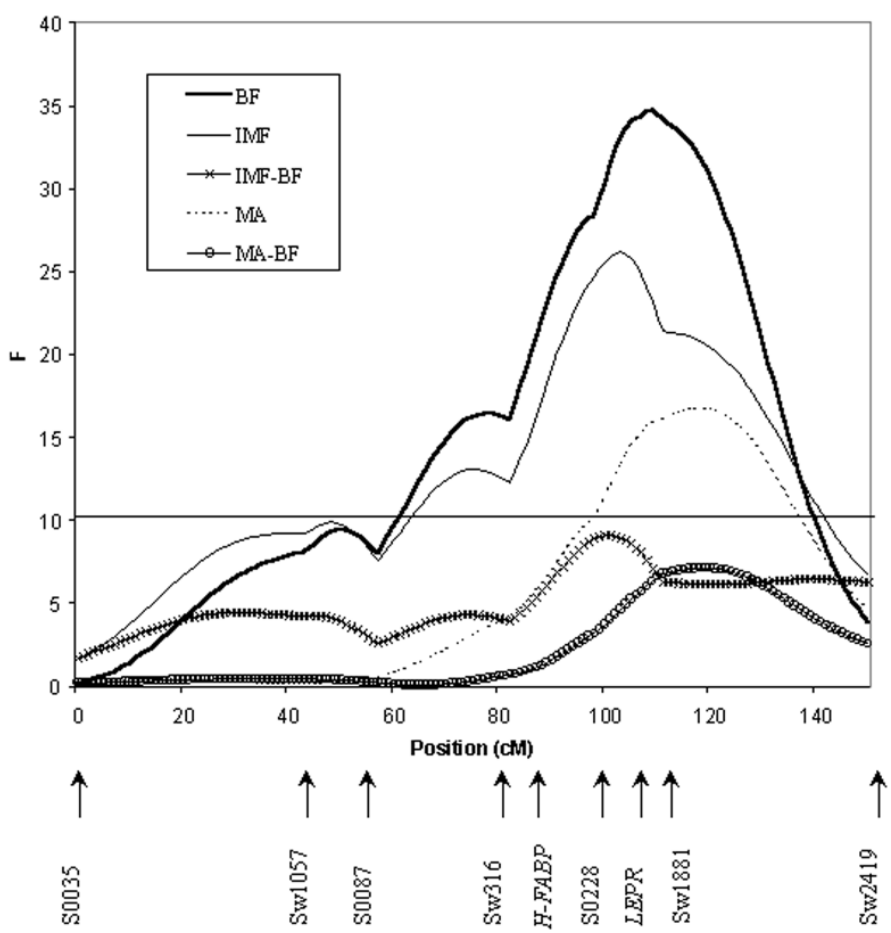

Figure 1. Test statistic curve (F value) across $\mathrm{Chr} 6$, for the traits BF, IMF and MA. (-BF indicates that BF has been included as the covariate in the statistical model instead of $\mathrm{CW}$ ). The horizontal line indicates the $1 \%$ genome-wide significance threshold.

$H$-FABP gene in the interval between the markers $S w 316$ and $S 0228$ ( $S w 316$ - $3.4 \mathrm{cM}-H-F A B P-12.5 \mathrm{cM}-S 0228)$, and the LEPR gene between the markers SO228 and Sw1881 (S0228 - 8.7 cM - LEPR - $3.6 \mathrm{cM}-S w 1881$ ). The distance covered with the nine markers was $150 \mathrm{cM}$ (sex averaged). As is usually reported in pigs, there was a significant difference in the length of the maps of the two sexes (164 cM in females and $141 \mathrm{cM}$ for males).

\subsection{QTL mapping}

The results of QTL regression analysis indicated the presence of one QTL on chromosome 6, with effects on BF, IMF and MA, as detected previously [24]. The inclusion of more $F_{2}$ genotypic information (animals and markers) resulted in a much higher significance and a similar effect and position of the QTL. The results of the new QTL analysis are shown in Table II and a graph of the F statistic value is given in Figure 1.

Maximum values of $F$ obtained for BF and IMF were located between the markers $S 0228$ and Sw1881, with confidence intervals 102-107 cM and 
Table II. Position on chromosome 6 and effect information of the higher $F$ value obtained for each trait ( $a$, additive effect; $d$, dominant effect) using different models of analysis including the candidate genes, $H-F A B P$ and $L E P R$ as the fixed effects.

\begin{tabular}{|c|c|c|c|c|c|c|}
\hline Trait & Covariate & $\begin{array}{l}\text { Candidate gene } \\
\text { as the fixed effect }\end{array}$ & $\begin{array}{l}\text { Position } \\
\text { (cM) }\end{array}$ & $a$ (s.e.) & $d$ (s.e.) & $\mathrm{F}^{\S}$ \\
\hline \multirow[t]{3}{*}{ BF } & $\mathrm{CW}$ & No & 109 & $4.11(0.54)$ & $-2.36(0.80)$ & $34.77^{\text {**** }}$ \\
\hline & & $H-F A B P$ & 109 & $4.31(0.58)$ & $-2.22(0.81)$ & $33.47^{* * *}$ \\
\hline & & $L E P R$ & 109 & $3.91(0.63)$ & $-2.38(0.80)$ & $25.68^{* * *}$ \\
\hline \multirow[t]{3}{*}{ IMF } & $\mathrm{CW}$ & No & 103 & $0.32(0.05)$ & $-0.17(0.07)$ & $26.17^{\text {*** }}$ \\
\hline & & $H-F A B P$ & 103 & $0.28(0.05)$ & $-0.20(0.07)$ & $20.11^{\text {*** }}$ \\
\hline & & $L E P R$ & 102 & $0.28(0.05)$ & $-0.18(0.07)$ & $16.91^{\text {*** }}$ \\
\hline \multirow[t]{3}{*}{ IMF } & BF & No & 101 & $0.19(0.05)$ & $-0.12(0.07)$ & $9.09^{*}$ \\
\hline & & $H-F A B P$ & 100 & $0.13(0.05)$ & $-0.16(0.07)$ & $5.65^{\mathrm{a}}$ \\
\hline & & $L E P R$ & 150 & $0.02(0.04)$ & $-0.21(0.06)$ & $6.45^{\mathrm{a}}$ \\
\hline \multirow[t]{3}{*}{ MA } & $\mathrm{CW}$ & No & 118 & $-1.85(0.42)$ & $2.27(0.68)$ & $16.76^{\text {*** }}$ \\
\hline & & $H-F A B P$ & 119 & $-1.87(0.45)$ & $2.26(0.70)$ & $15.27^{\text {*** }}$ \\
\hline & & $L E P R$ & 118 & $-1.85(0.42)$ & $2.27(0.68)$ & $14.70^{\text {*** }}$ \\
\hline \multirow[t]{3}{*}{ MA } & $\mathrm{BF}$ & No & 119 & $-1.07(0.48)$ & $2.20(0.74)$ & $7.13^{\mathrm{a}}$ \\
\hline & & $H-F A B P$ & 120 & $-0.93(0.51)$ & $2.20(0.76)$ & $5.97^{\mathrm{a}}$ \\
\hline & & $L E P R$ & 119 & $-1.10(0.53)$ & $2.20(0.74)$ & $6.87^{\mathrm{a}}$ \\
\hline
\end{tabular}

$\S$ F-values with ${ }^{*}$ and ${ }^{* * *}$ superscripts exceed the 5 and $0.1 \%$ genome-wide significance thresholds $(F=8.53$ and 13.07);

a superscript indicates $F$-values exceeding the 5\% chromosome-wide threshold $(F=5.20)$.

96-108 cM, respectively. The maximum $F$ value for MA was located in the following marker bracket ( $S w 1881-S w 2419)$, within the confidence interval $105-129 \mathrm{cM}$. Iberian alleles increased fatness traits and decreased muscle area as could be expected, and showed partial (BF and IMF) or complete (MA) recessivity. The differences between homozygotes for Iberian and Landrace alleles were the same as those described in Óvilo et al. [24], since the additive and dominant effects obtained were almost identical to the ones previously reported. The values of the fraction of the phenotypic variances explained by the QTL $\left(h_{\mathrm{QTL}}^{2}\right)$ ranged from 0.07 to 0.17 . Analysis of IMF and MA data with $\mathrm{BF}$ as a covariate resulted in a great reduction of significance and effect. The results concerning position and additive and dominant effects of the QTL were very similar when models that include the effects of the candidate gene were used (Tab. II), except for the IMF trait with BF as the covariate, in which the inclusion of the $L E P R$ genotypes as fixed effects results in a reduction of the QTL significance and effect, and a change in the QTL position. 
Table III. Additive and dominant effects on the different traits of the candidate gene $H-F A B P(H a e I I)$ included in the model of analysis as a fixed effect. Results from two approaches using an animal model (AM) or a QTL regression analysis (QTL-M).

\begin{tabular}{lcccc}
\hline Trait & Covariable & Model & Additive effect (s.e) & Dominant effect (s.e) \\
\hline BF & CW & AM & $1.13(0.65)$ & $-0.73(0.78)$ \\
& & QTL-M & $-0.23(0.81)$ & $-1.09(0.86)$ \\
IMF & CW & AM & $0.17(0.05)^{* *}$ & $0.06(0.06)$ \\
& & QTL-M & $0.07(0.07)$ & $0.09(0.07)$ \\
IMF & \multirow{2}{*}{ BF } & AM & $0.15(0.04)^{* *}$ & $0.08(0.06)$ \\
& & QTL-M & $0.10(0.07)$ & $0.14(0.07)$ \\
MA & CW & AM & $-0.90(0.41)^{*}$ & $1.25(0.50)^{*}$ \\
& & QTL-M & $0.42(0.54)$ & $1.15(0.60)$ \\
\hline
\end{tabular}

$*$ and ${ }^{* *}$ superscripts exceed the 5 and $1 \%$ significance thresholds.

\subsection{Candidate gene analysis}

The $H-F A B P$ polymorphism is segregating in both parental lines, the frequency of allele $D$ in Guadyerbas and Landrace parental populations being 0.5 and 0.3 , respectively. In the $\mathrm{F}_{2}$ population the frequency of allele $D$ is 0.3 .

Informativeness of the $L E P R$ gene polymorphism for the candidate gene analysis was limited due to the low frequency of one of the alleles in the parental population (the frequency of allele $A$ was 0.2 in Landrace and 0 in Guadyerbas). In the $\mathrm{F}_{2}$ population, the frequency of allele $A$ was 0.08 , the $A A$ genotype was absent.

Results of the $H-F A B P$ and $L E P R$ association analysis are shown in Tables III and IV, respectively, and important discrepancies were observed for the two compared methods of statistical analysis.

When using the QTL regression model, no significant effect of the $H$-FABP gene on the analyzed traits was observed, and the $L E P R$ gene only showed an effect on IMF corrected for BF $(P<0.05)$. But, when an animal model was used and the QTL effects were ignored, several significant associations between traits and candidate genes were found. For intramuscular fat percentage a significant association with the $H-F A B P$ genotypes was detected. The genotype $D D$ showed the highest content of intramuscular fat, the difference with respect to the other homozygous genotype being $0.33 \pm 0.10 \%(P<0.002)$. Due to the correlation existing between the two fatness traits IMF and BF, the analysis was repeated using $\mathrm{BF}$ as the covariate in the model, and the results obtained were similar to the first ones. When the IMF data was corrected for BF, the contrast between the homozygous genotypes $(D D-d d)$ was $0.30 \pm 0.08 \%(P<0.003)$. The estimate of the dominance effect was not significant for this trait in the two 
Table IV. Genotype effects $(B B-A B)$ on the different traits of the candidate gene $L E P R$ (HpaII) included in the model of analysis as a fixed effect. Results from two approaches using an animal model (AM) or a QTL regression analysis (QTL-M).

\begin{tabular}{lccc}
\hline Trait & Covariable & Model & BB-AB Contrast \\
\hline BF & CW & AM & $2.96(0.94)^{* *}$ \\
& & QTL-M & $0.77(1.22)$ \\
IMF & CW & AM & $0.26(0.08)^{* *}$ \\
& & QTL-M & $0.15(0.10)$ \\
IMF & BF & AM & $0.13(0.07)$ \\
& & QTL-M & $0.27(0.09)^{*}$ \\
MA & CW & AM & $-0.46(0.60)$ \\
& & QTL-M & $-0.01(0.80)$ \\
\hline
\end{tabular}

${ }^{*}$ and ${ }^{* *}$ superscripts exceed the 5 and $1 \%$ significance thresholds.

cases. The additive effect of this polymorphism on IMF is equivalent to 0.3 phenotypic standard deviations. For BF there were no significant results for any contrast, although the additive effect approached significance. Eye muscle area analysis showed significant results for the two contrasts. The allele responsible for a higher muscle area was the opposite to that of higher fatness traits, with a difference between the homozygous genotypes $D D-d d=-1.81 \pm 0.82 \mathrm{~cm}^{2}$ $(P<0.029)$. The dominance effect estimated was $1.25 \pm 0.50 \mathrm{~cm}^{2}(P<0.012)$.

The $L E P R$ polymorphism showed a significant association with $\mathrm{BF}$ and IMF traits in the analysis with the animal model, but not with MA. The difference of $\mathrm{BF}$ between the two available genotypes was $B B-A B=2.96 \pm 0.94 \mathrm{~mm}$ $(P<0.0018)$ and for IMF this difference was $0.26 \pm 0.08 \%(P<0.0012)$. The significance and effect of this gene on IMF was greatly reduced when BF was introduced as the covariate in the model $(B B-A B=0.13 \pm 0.07, P<0.068)$.

\section{DISCUSSION}

We previously described the existence of a QTL on porcine chromosome 6, with a highly significant effect on backfat and intramuscular fat percentage. This result could be interesting for pig breeding programs since DNA technology could help to improve the marbling level of pork meat. The combination of marker assisted introgression of this and other loci and conventional selection methods would achieve a higher intramuscular fat without increasing the levels of other fat depots like backfat.

The application of the results found in this previous study requires the fine mapping of the QTL and ideally the identification of the causal mutation/s responsible for the effect. A first step could be to increase the precision and 
significance of the mapping by genotyping more markers and as many animals as possible. In the present work, we genotyped microsatellites in $134 \mathrm{~F}_{2}$ additional animals, that is in all $\mathrm{F}_{2}$ populations except in the families with very low informativeness. All the $\mathrm{F}_{2}$ pigs have been genotyped for $H-F A B P$ and $L E P R$ polymorphisms. The results of this new analysis showed a very much increased significance level of the chromosome 6 fatness QTL. The position and the size of the effect did not seem to be modified, the difference between homozygotes for alternative alleles of the QTL being $9 \mathrm{~mm}$ in BF, $0.7 \%$ in IMF and $4 \mathrm{~cm}^{2}$ in MA. This corresponds to an additive effect of $0.3-0.6$ phenotypic standard deviations.

The results of the present work allowed us to map the QTL with a higher precision. However, to confirm the presence of the QTL it would be necessary to analyze other populations in the future. For this purpose we could analyze more generations of our experimental population or other commercial populations. Those could be studied with new statistical methods, such as Transmission Disequilibrium Tests, which has been shown to be very helpful to map genes for quantitative traits in commercial pigs [1].

Fine mapping of the QTL region in combination with selection of candidate genes is a way to localize and characterize the genes underlying the QTLs. In this study, two positional candidate genes were evaluated for the chromosome 6 QTL (103-109 cM), the $H-F A B P$ and $L E P R$ genes.

The first aim of this candidate gene association work was to locate these genes in the microsatellite map, obtained in the QTL detection experiment, to look for a coincidence in position. The results showed a nearly identical location of the $L E P R$ gene with respect to the fatness QTL, both located in the same marker bracket ( $S 0228-S w 1881$ ), with a distance of only $3 \mathrm{cM}$ from the IMF maximum $F$ value and $2 \mathrm{cM}$ from the BF maximum $F$ value. $H-F A B P$ is located in the previous marker bracket $(S w 316-S 0228), 17 \mathrm{cM}$ apart from the QTL and out of its confidence interval.

The results of the analysis of the effects of the candidate genes are dependent on the model used. The main difference between both models concerns the inclusion of the probabilities of the parental origin of the QTL alleles, which is ignored in the animal model used. The association analysis with the animal model, shows positive results for the two candidate genes. The $H$-FABP gene is, according to our results, associated with IMF and MA, but not with BF. This result is not concordant with the first reports which described a main effect of this gene on BF [8], although more recent works have described this association with only IMF $[9,13,14]$. Moreover the effect of the gene on IMF in our population was independent of BF content, since the introduction of $\mathrm{BF}$ as the covariate in the model did not modify the results, contrarily to those reported by Gerbens et al. [8]. There are other papers that have also described no association of this gene with fatness traits [2]. On the contrary the allele 
responsible for a higher fatness level was the opposite in our population than in others. If we compare the effect observed for the $H-F A B P$ polymorphism with the effect of the QTL detected previously, we can see important differences, since the main effect of the QTL is on BF and the IMF effect is greatly reduced with the introduction of $\mathrm{BF}$ as the covariate, in contrast to the $H$ $F A B P$ association results. The effect of the $H-F A B P$ gene on MA is not easily explained by the gene function and has not been reported previously.

In contrast to these association results, those obtained using the model of QTL regression analysis, with the $H-F A B P$ genotype included as the covariate, do not indicate any effect of the H-FABP (HaeIII) polymorphism on any analyzed trait. This dependence on the analytical model and the quoted differences in the results obtained in other experiments suggest that the polymorphism responsible for the effect found is not the PCR-RFLP analyzed, but another close polymorphism linked in different phases depending on the population. Moreover, in a recent work Gerbens et al. [10] could not explain the variation of IMF in crossbred pigs by differences in mRNA and protein expression levels of $H$-FABP HaeIII genotypes, although these negative results could be due to limitations of the assays. Although we can conclude that our polymorphism is not the causal mutation of the effect observed, it could have a practical interest as a marker for pig breeding programs aimed at improving meat quality while avoiding a backfat increase. If this polymorphism and the causal mutation are closely linked, we would expect a linkage disequilibrium in the commercial populations subjected to genetic improvement programs; then if the association could be confirmed it would be possible to include the polymorphism for marker assisted selection, without the need for determining linkage phases within families.

The results of the $L E P R$ gene association analysis using the animal model showed a significant effect of this gene on BF and IMF. The magnitude of this association seems to be high since the difference between the two available genotypes on BF corresponds to 0.37 phenotypic standard deviations, but unfortunately the limited informativeness of the polymorphism analyzed did not allow to estimate the additive and dominant effect of this gene on the productive traits. This result agreed with the recent description of the association of this gene with productive traits, mainly with BF [18]. These association results are more concordant with the QTL effect than the previous candidate gene since the main effect of the $L E P R$ gene is on BF, and the IMF effect is greatly reduced when $\mathrm{BF}$ is introduced as the covariate in the model. Nevertheless the polymorphism analyzed has very low frequencies in both parental breeds to explain the phenotypic differences between them.

Furthermore, when using the QTL regression analysis with the LEPR polymorphism genotypes included as fixed effects, we could not detect any effect of this polymorphism on the phenotypic traits. 
Candidate gene analyses are usually performed in experimental crosses by the application of models where the QTL effects are not fitted [9]. When these kinds of models are used, the linkage disequilibrium between the real QTL and the candidate gene could lead to a wrong association for the candidate gene. In fact, in this type of experimental crosses of divergent lines it is highly probable to find associations for all the polymorphic loci that, mapping close to the QTL, had different frequencies in the parental lines. Nevertheless, the QTL regression approach separates the QTL effect from the candidate gene effect giving more reliable results. Taking this into account, the interpretation of the results of candidate gene studies must be careful in order to avoid false associations.

The inclusion of the effect of the candidate gene in the QTL regression model gives better results than the animal model, because it takes into account the information of the markers; but neither of the two models is able to find the causal mutations. On the contrary, the QTL regression model, with the effect of the candidate gene included, could present collinearity problems when the candidate gene and the QTL are very close, and the candidate gene has alternative alleles fixed in each parental breed. This was not the case for the polymorphisms analyzed in this work, which are not very informative, but it could be an important limitation of this model for the analysis of the most promising candidate gene polymorphisms. When the candidate gene has different alleles fixed alternatively in the parental populations, it is impossible to statistically distinguish the effects of the candidate gene and the QTL. Then, the most useful polymorphisms for this type of analysis would not be the most informative ones, and the ideal polymorphism would be that for which frequencies in parental lines are different but not completely different (not fixed). In contrast, the microsatellite informativity increases the power for QTL detection, and the optimum results are obtained when the microsatellites have different alleles in parental populations.

The ensemble of the results of the present work suggests that the polymorphisms analyzed are not causal mutations but only markers in linkage disequilibrium with them, located in these or closely linked genes. The physiological function of these two candidate genes suggests that the observed effects should be due to mutations located in regulatory or coding regions of these genes. Leptin and related proteins such as the leptin receptor are implicated in the regulation of food intake and fatness, the traits showing strong differences between the parental breeds. The chromosomal position of the LEPR gene and the observed effect of the Hpa II polymorphism on intramuscular fat allows us to suppose that this gene could be responsible for some of the QTL effects found in chromosome 6. Although the $H-F A B P$ gene maps on a more distant position from the QTL than the $L E P R$ gene, its functional role in the intracellular transport of fatty acids in muscle justifies continuing the study of 
this candidate gene. Two others polymorphisms were screened for the $H$-FABP gene and one for the $L E P R$ gene, which were not informative in our population. The search for new polymorphisms in coding regions of these candidate genes, with an influence on the structure or composition of the coded protein, is badly needed to try to find the causal mutations influencing fatness and quality traits in this experimental cross.

\section{ACKNOWLEDGEMENTS}

We thank N. López and J. Pérez for technical assistance. We are also grateful to all the personnel in Nova Genètica and Copaga, J. Estany and D. Babot for help throughout the project, A. Quintana and M. Arqué for technical assistance, C. Haley for the regression software, P. Green for CRIMAP and D. Milan for GEMMA software. M. Rothschild and the US National Genome program NRSP-8 kindly provided the microsatellite primers. The Guadyerbas boars were a gift from the SIA 'El Dehesón del Encinar'(Toledo, Spain) and the rest of the animals were produced in Nova Genética. A. Clop was funded by a fellowship from Universitat Autónoma de Barcelona. Work was funded by grants AGF99-0284-C02-01 and SC00-057.

\section{REFERENCES}

[1] Bink M.C.A.M., Te Pas M.F.W., Harders F.L., Janss L.L.G., A transmission disequilibrium test approach to screen for quantitative trait loci in two selected lines of Large White pigs, Genet. Res. (2000) 115-121.

[2] Chen Y., Kerr R.J., Lee J.H., Luxford B.G., Moran C., Effect of H-FABP gene variants on intramuscular fat in commercial pigs in Australia, in: 27th International Conference on Animal Genetics, Minnestota, July 22-26, 2000, Conference Abstract Book, International Society of Animal Genetics, University of Minnesota, Minnesota, 2000, p. 35.

[3] Churchill G.A., Doerge R.W., Empirical threshold values for quantitative trait mapping, Genetics 138 (1994) 963-971.

[4] De Koning D.J., Rattink A.P., Harlizius B., Van Arendonk J.A.M., Brascamp E.W., Groenen M.A.M., Genome wide scan for body composition in pigs reveals important role of imprinting, Proc. Natl. Acad. Sci. USA 97 (2000) 7947-7950.

[5] Ernst C.W., Kapke P.A., Yerle M., Rothschild M.F., The leptin receptor gene (LEPR ) maps to porcine chromosome 6, Mamm. Genome 8 (1997) 226.

[6] Friedman J.F., Halaas J.L., Leptin and the regulation of body weight in mammals, Nature 395 (1998) 763-770.

[7] Gerbens F., Rettenberger G., Lenstra J.A., Veerkamp J.H., te Pas M.F.W., Characterization, chromosomal localization and genetic variation of the porcine heart fatty acid binding protein gene, Mamm. Genome 8 (1997) 328-332. 
[8] Gerbens F., Van Erp A.J.M., Harders F.L., Verburg F.J., Meuwissen T.H.E., Veerkamp J.H., Te Pas M.F.W., Effect of genetic variants of the heart fatty acid binding protein gene on intramuscular fat and performance traits in pigs, J. Anim. Sci. 77 (1999) 846-852.

[9] Gerbens F., de Koning D.J., Harders F.L., Meuwissen T.H.E., Janss L.L.G., Groenen M.A.M., Veerkamp J.H., Van Arendonk J.A.M., te Pas M.F.W., The effect of adipocyte and heart fatty acid binding protein genes on intramuscular fat and backfat content in Meishan crossbred pigs, J. Anim. Sci. 78 (2000) 552-559.

[10] Gerbens F., Verburg F.J., Van Moerkerk H.T.B., Engel B., Buist W., Veerkamp J.H., te Pas M.F.W., Associations of the heart and adipocyte fatty acid-binding protein gene expression with intramuscular fat content in pigs, J. Anim. Sci. 79 (2001) 347-354.

[11] Gispert M., Faucitano L., Oliver M.A., Guardia M.D., Coll C., Siggens K., Harvey K., Diestre A., A survey of pre-slaughter conditions, halothane gene frequency, and carcass and meat quality in five Spanish pig commercial abattoirs, Meat Sci. 55 (2000) 97-106.

[12] Green P., Falls K., Crooks S., Documentation of CRI-MAP. Unpublished mimeo (http://biobase.dk.Embnetut/Crimap), 1990.

[13] Grindflek E., Szyda J., Rothschild M.F., Lien S., A QTL analysis and candidate gene study for meat quality on swine chromosome 6, in: International Plant and Animal Genome VIII Conference, San Diego, California, January 9-12, 2000, (http://www.intl-pag.com/8/).

[14] Grindflek E., Szyda J., Liu Z., Lien S., Detection of quantitative trait loci for meat quality in a commercial slaughter pig cross, Mamm. Genome 12 (2001) 299-304.

[15] Groeneveld E., Kovac M., Wang T., Pest, a general purpose BLUP package for multivariate prediction and estimation, in: Hill W.G., Thompson R., Woolliams J.A. (Eds.), Proceedings of the 4th World Congress on Genetics Applied to Livestock Production, Edinburgh, July 23-27, 1990, vol. 13, pp. 488-491.

[16] Guerrero L., Gou P., Alonso P., Arnau J., Study of the physicochemical and sensorial characteristics of dry cured hams in three genetic types, J. Sci. Food. Agric. 70 (1996) 526-530.

[17] Haley C.S., Knott S.A., Elsen J.M., Mapping quantitative trait loci in crosses between outbred lines using least squares, Genetics 136 (1994) 1195-1207.

[18] Hardge T., Siebel K., Koepke K., Wimmers K., Association between Leptin $(L E P)$ / Leptin Receptor (LEPR) polymorphisms and fatness related traits in a porcine resource family, in: 27th International Conference on Animal Genetics, Minnestota, July 22-26, 2000, Conference Abstract Book, International Society of Animal Genetics, University of Minnesota, Minnesota, 2000, p. 65.

[19] Knott S.L., Marklund L., Haley C., Andersson K., Davies W., Ellegren H., Fredholm M., Hansson I., Hoyheim B., Lundstrom K., Moller M., Andersson L., Multiple marker mapping of quantitative trait loci in a cross between outbred wild boar and Large White pigs, Genetics 149 (1998) 1069-1080.

[20] Mangin B., Goffinet B., Rebai A., Constructing confidence intervals for QTL location, Genetics 138 (1994) 1301-1308. 
[21] Morales J., Pérez J.F., Baucells M.D., Gasa A., Gasa J., Comparative digestibility and productive performances between Landrace and Iberian pigs fed on a corn or a sorghum - acorn - based diet, in: 8th Symposium on Digestive Physiology in Pigs, Uppsala, Sweden, June 20-22, 2000, CABI Publishing, Ed. Linberg and Bogle, 2000, pp. 227-229.

[22] Neumaier A., Groeneveld E., Restricted maximum likelihood estimation of covariances in sparse linear models, Genet. Sel. Evol. 30 (1998) 3-26.

[23] Oliver M.A., Gou P., Gispert M., Diestre A., Arnau J., Noguera J.L., Blasco A., Comparison of five types of pig crosses II. Fresh meat quality and sensory characteristics of dry cured ham, Livest. Prod. Sci. 40 (1994) 179-185.

[24] Ovilo C., Pérez-Enciso M., Barragán C., Clop A., Rodríguez C., Oliver M.A., Toro M.A., Noguera J.L., A QTL for intramuscular fat and backfat thickness is located on porcine chromosome 6, Mamm. Genome 11 (2000) 344-346.

[25] Rothschild M.F., Plastow G.S., Current advances in pig genomics and industry applications, AgBiotech. Net 1 (1999) 1-7.

[26] Serra X., Gil F., Pérez-Enciso M., Oliver M.A., Vázquez J.M., Gispert M., Díaz I., Moreno F., Latorre R., Noguera J.L., A comparison of carcass, meat quality and histochemical characteristics of Iberian (Guadyerbas line) and Landrace pigs, Livest. Prod. Sci. 56 (1998) 215-223.

[27] Stratil A., Kopecny M., Moser G., Schroffel J., Cepica S., HpaII and RsaI PCRRFLPs within an intron of the porcine leptin receptor gene (LEPR) and its linkage mapping, Anim. Genet. 29 (1998) 398-413.

[28] Wood J.D., Wiseman J., Cole D.J.A., Control and manipulation of meat quality, in: Cole D.J.A., Wiseman J., Varley M.A. (Eds.), Principles of pig science, Nottingham University Press, Leicestershire, 1994, pp. 433-456.

To access this journal online: www.edpsciences.org 